\title{
Polymer biodegradable coatings as active substance release systems for urological applications
}

\author{
Małgorzata Borowska' ${ }^{1}$ (D) Marta Glinka ${ }^{1} \cdot$ Natalia Filipowicz ${ }^{2} \cdot$ Agata Terebieniec $^{2} \cdot$ Paweł Szarlej $^{3}$. \\ Agata Kot-Wasik ${ }^{1} \cdot$ Justyna Kucińska-Lipka ${ }^{3}$
}

Received: 28 February 2019 / Revised: 9 June 2019 / Accepted: 24 June 2019 / Published online: 13 August 2019

(c) The Author(s) 2019

\begin{abstract}
Catheter-associated urinary tract infections are the result of catheterization of the bladder. The risk of infection is directly proportional to the length of the bladder catheterization. Bacteria cells have the ability to adhere and create the biofilm on the surface of catheter materials. Bacteria's biofilm is an extremely beneficial environment of existence for microorganisms. Microorganisms that are an integral part of the biofilm are characterized by a higher resistance to antimicrobial agents compared to the planktonic form of bacteria. The previous treatment of urinary tract infections presupposes the necessity of the oral administration of large amounts of antimicrobial agents. An alternative may be the use of antimicrobial and antiadhesion coatings on the surface of the catheters. These coatings may allow target drug delivery and contribute to dose reduction and improved drug availability. In this study, antimicrobial coatings from biodegradable polymers with clindamycin were evaluated. The antimicrobial activity of the prepared coatings against selected bacterial strains was determined. The highperformance liquid chromatography-mass spectrometry technique was applied for the analysis of the drug release from antimicrobial coatings.
\end{abstract}

\section{Graphic abstract}

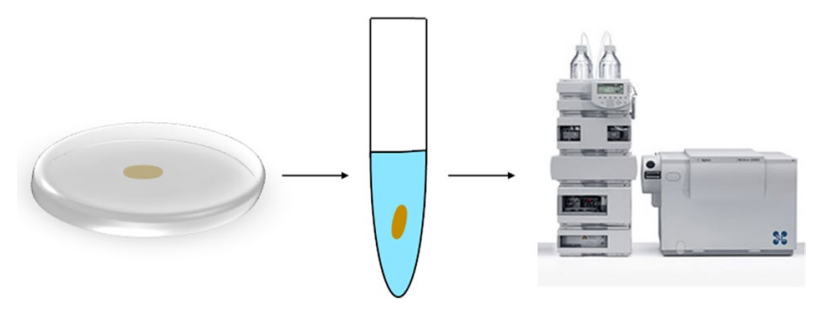

Keywords Antimicrobial polymer coatings · Catheterization · High-pressure liquid chromatography · Urinary catheter · Urinary tract infections

Małgorzata Borowska

malborow@student.pg.edu.pl

1 Department of Analytical Chemistry, Faculty of Chemistry, Gdańsk University of Technology, 11/12 Gabriela Narutowicza Street, 80-233 Gdańsk, Poland

2 Department of Molecular Biotechnology and Microbiology, Faculty of Chemistry, Gdańsk University of Technology, 11/12 Gabriela Narutowicza Street, 80-233, Gdańsk, Poland

3 Department of Polymer Technology, Faculty of Chemistry, Gdańsk University of Technology, 11/12 Gabriela Narutowicza Street, 80-233 Gdańsk, Poland

\section{Introduction}

Urinary catheters are used, when the natural urinary excretion is hindered. Bladder catheterization can be used to accurately assess the amount of urine output. Short-term catheterization is given to patients undergoing some surgical procedures. One of the indications for catheterization of the urinary bladder is the state of urinary retention associated with bladder inflammation. Catheters are also used after urological procedures to heal the urinary tract. The most common complication after catheterization is urinary tract 
Fig. 1 The steps of formation of bacteria's biofilm [11]

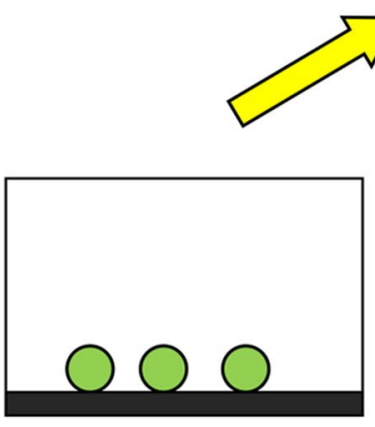

(a) Adsorption

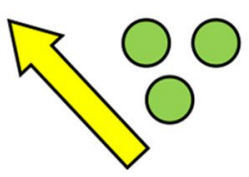

(e) Dispersion

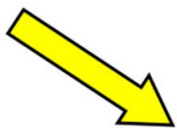

(b) Irreversible Attachment

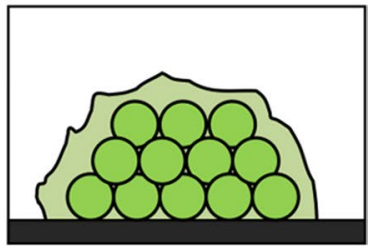

(c) Growth and Division
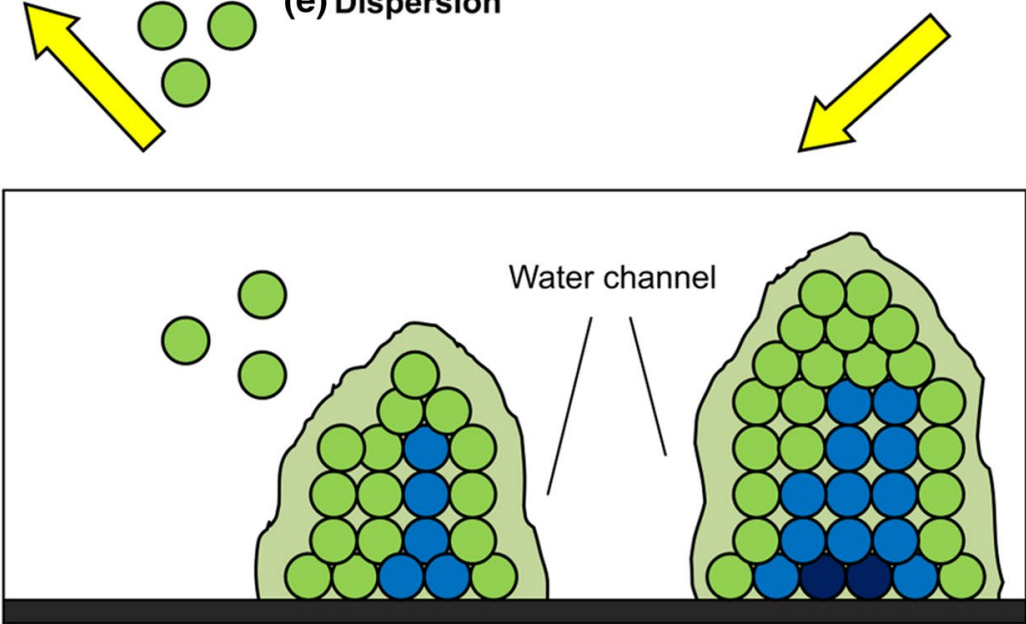

(d) Mature Macrocolony

Planctonic cells

Sessile resistant core infections (UTIs) [1]. UTIs are the most common healthcareassociated infections and make up to about $40 \%$ of all infections in hospitalized patients. CAUTI (catheter-associated urinary tract infections) constitute for $80 \%$ of UTI [2].

Catheterization may lead to the disruption of the natural defense system of the urinary tract and can enable colonization of the bacteria. Microbes that are in the urine have the ability to adhere on the surface of the catheter materials and can create a biofilm on this surface. The formation of urinary tract infections is associated with the presence of a bacterial biofilm [3].

The risk of developing UTIs is directly proportional to the length of the bladder catheterization. Catheterization, which lasts less than 7 days, contributes to the occurrence of infections in almost $50 \%$ of patients. Long-term catheterization (up to 28 days) can result in an increase in the risk of infection to $100 \%$ [2].

Biofilm formation is a highly complex process. Microorganism cells transform from planktonic to the sessile mode of growth. The stages of biofilm formation are shown in
Fig. 1. Biofilm formation consists of the following steps: initially, attachment of microorganisms cells to the colonized surface (Fig. 1a), formation of micro-colony (Fig. 1b), threedimensional structure formation (Fig. 1c), biofilm formation, maturation (Fig. 1d), and detachment of cells (Fig. 1e). In the initial phase of biofilm formation, single bacterial cells (planktonic form of bacteria) attach to the biomaterial surface. In the second stage, the bacterial cells are permanently bound to the surface of the biomaterial. During the third stage, adhesion of the microorganism cells occurs and a micro-colony is created followed by intense cell division. In the next step, an intensive increase in biofilm is observed. At the time of biofilm maturation, genes' expression changes. Finally, single bacterial cells are released from the mature biofilm. The released cells have the ability to occupy new surfaces of the biomaterial [4].

Bacteria's biofilm is an extremely beneficial environment of existence for microorganisms. Microorganisms living in this structure seem to have a significant advantage over planktonic forms. Microbes that are an integral part of 
the biofilm show greater resistance (up to 1000-fold times higher) to agents used for their degradation compared to the planktonic form of bacteria [5]. In addition, the catheter colonized by microorganisms must be replaced with new ones, which results in increased patient morbidity and increased costs involved in the healthcare system [3].

The treatment of urinary tract infections requires the use of large amounts of antimicrobial substances. The alternative may be to prevent infection. It is possible to develop catheters made of materials that prevent the adhesion of microorganisms and formation of biofilm [3]. An effective choice is the coating of the catheter surface with antimicrobial agents or using polymer coating that contains antimicrobial agents [5]. The polymer coating should be degradable, so that during the dissolution, the drug substances are released at the appropriate rate.

The most popular materials used to manufacture catheters are polyvinyl chloride (PVC), polyurethanes, silicones, and latex gums. These materials have the properties desired in urinary catheters, which include: high tensile strength, soft and elastic structure, chemical resistance, biocompatibility, ability to meet urinary flow requirements while maintaining a minimally invasive circumference [6].

The aim of this study was to evaluate antimicrobial coatings from biodegradable polymers like polyvinyl alcohol (PVA) and polyvinylpyrrolidone (PVP) with clindamycin as an antimicrobial agent. Antimicrobial activity of PVP-clindamycin coatings was tested against three different bacteria clindamycin-sensitive strains: Escherichia coli, Pseudomonas aeruginosa, and Staphylococcus aureus. The strains of microorganisms belonging to these bacterial species were previously reported as present in catheter-related infections [3].

\section{Results and discussion}

\section{Characterization of PVA and PVP coatings}

Polymeric coatings containing 1, 3, 5, and 7\% of PVA and PVP were prepared by dissolving the appropriate amount of polymer in deionized water. After the dissolution of the entire polymer, the solutions were poured into $9 \mathrm{~cm}$ Petri dishes for drying. The PVP-based coatings were characterized by a shorter drying time compared to PVA-based coatings.

In the next step, the mechanical properties of coatings were examined and the tensile strength $\left(T_{\mathrm{Sb}}\right)$ values for coatings with different PVA and PVP content are presented in Table 1. If the polymer content in the coating is high, the tensile strength of the coating will also be high. The PVPbased coatings were characterized by better mechanical
Table 1 Mechanical properties of coating based on PVA and PVP

\begin{tabular}{lrl}
\hline $\begin{array}{l}\text { Polymer content in the coat- } \\
\text { ing/\% }\end{array}$ & \multicolumn{2}{l}{$T_{\text {sb }} / \mathrm{kPa}$} \\
\cline { 2 - 3 } & \multicolumn{1}{l}{ PVA } & \multicolumn{1}{l}{ PVP } \\
\hline 1 & $5.0 \pm 0.3$ & $15.0 \pm 0.1$ \\
3 & $11.0 \pm 0.2$ & $20.0 \pm 0.2$ \\
5 & $13.0 \pm 0.1$ & $21.0 \pm 0.1$ \\
7 & $10.0 \pm 0.1$ & $24.0 \pm 0.1$ \\
\hline
\end{tabular}

strength compared to PVA-based coatings. Therefore, coatings made of PVP were selected for further studies.

The physicochemical properties of PVP coatings were also examined. Coatings with different PVP concentrations were observed using optical microscopy to assess their homogeneity. The degradation of coatings after the impact of $0.9 \% \mathrm{NaCl}$ was also tested. Coatings containing 1 and $3 \%$ PVP are characterized by a homogeneous structure, while for $5 \%$ and $7 \%$, the amount of PVP in coatings is not homogeneous. The coating containing 1\% PVP turned out to be brittle and unstable when in contact with $0.9 \% \mathrm{NaCl}$ (too fast solubility). This coating cannot be used in further studies. Other coatings $(3,5,7 \%)$ showed characteristics of good flexibility, sufficient durability and slower degradation than the coating which includes $1 \%$ of PVP. In this step, the coating containing $3 \%$ of PVP was chosen to prepare coatings with different concentrations of clindamycin $(1,3$, and $5 \%)$.

\section{Microbiology test}

Polymeric coatings containing 3\% of PVP and different amounts of clindamycin $(1,3,5 \%)$ were subjected to interaction with the clindamycin-sensitive strains of Escherichia coli, Pseudomonas aeruginosa, and Staphylococcus aureus bacterial strains. Antibacterial activities of these coatings were evaluated by using the disk agar diffusion method [7]. Polymeric coatings containing 3\% of PVP without addition of clindamycin was also subjected to interaction with these three microorganisms.

The polymer coatings based on PVP without the addition of clindamycin did not inhibit the growth of any tested bacterial strains. Hence, we conclude that PVP material achieved and used during this study did not reveal any antimicrobial activity. In the case of polymeric PVP coatings containing clindamycin, inhibition of the examined bacterial strains was observed to varying degrees depending on the content of clindamycin in the coating. In the case of $P$. aeruginosa bacterial strain, clear zones of growth inhibition were observed only for coatings containing 5\% clindamycin. For other analyzed bacterial species, the clear zones of growth inhibition were clear around all analyzed samples. The used Pseudomonasaeruginosa strain seems to be less sensitive 
Table 2 Diameters of growth inhibition zones of three bacterial strains against PVPclindamycin coatings

\begin{tabular}{llcl}
\hline The content of clindamycin in the & \multicolumn{2}{l}{ Diameters of growth inhibition zones/cm } \\
\cline { 2 - 4 } PVP-based coating/\% & E. coli & P. aeruginosa & S. aureus \\
\hline 0 & No zone to inhibit bacterial growth (three repeats) & \\
1 & $D=4.42 \pm 0.44$ & No visible zone of & $D=3.94 \pm 0.24$ \\
& $d=3.75 \pm 0.22$ & bacterial growth & $d=3.61 \pm 0.20$ \\
& & inhibition & \\
3 & $D=4.021 \pm 0.036$ & No visible zone of & $D=4.56 \pm 0.29$ \\
& $d=3.44 \pm 0.22$ & bacterial growth & $d=3.58 \pm 0.40$ \\
& & inhibition & \\
5 & $D=4.56 \pm 0.29$ & $D=4.00 \pm 0.25$ & $D=4.69 \pm 0.47$ \\
& $d=3.58 \pm 0.40$ & $d=3.60 \pm 0.10$ & $d=4.32 \pm 0.45$ \\
\hline
\end{tabular}

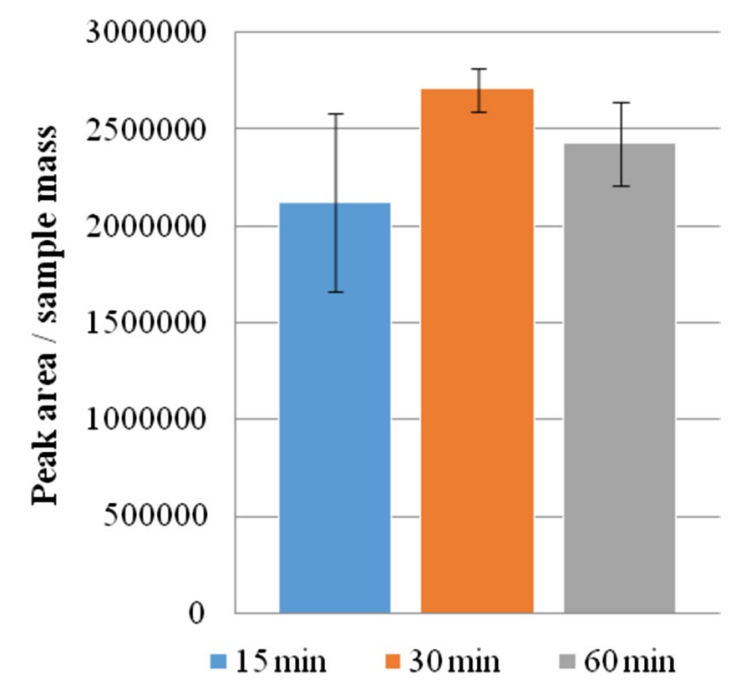

Fig. 2 Release of clindamycin from PVP-based coatings

on the antibacterial activity of clindamycin than E. coli and Staphylococcus aureus strains. The size of polymer coatings prepared for this microbiological study was not the same for all the investigated cases. The diameters of growth inhibition zones of bacterial strains against polymeric coatings containing different clindamycin contents are shown in Table 2. The zones of growth inhibition are ellipses. The diameters values of both the ellipses are presented in the table.

\section{Clindamycin release from antimicrobial coatings}

The analysis of the clindamycin release rate from coatings containing 3\% of PVP was carried out using HPLC-MS. Antimicrobial coating fragment was placed in a saline solution for a specified time $(15,30,60 \mathrm{~min})$. After 15 , 30 and $60 \mathrm{~min}$, a sample of the solution was taken for the chromatographic analysis based on HPLC-MS. The results are shown in Fig. 2 and are presented as the ratio of the peak area to the mass coating immersed in the solution as a function of time.

The release of clindamycin from coatings was defined as the dissolution of PVP with the simultaneous release of clindamycin. After the first time interval (15 min), 80\% of clindamycin was eluted. After the next $15 \mathrm{~min}$, the maximal concentration of drug in the saline solution was recorded. After the third point of time (60 $\mathrm{min})$, approximately $90 \%$ of clindamycin was released from the coating.

The release of clindamycin from PVP-based coatings happens quickly. The maximum concentration of clindamycin in the saline solution was already reached after $30 \mathrm{~min}$. Then, the drug concentration in the solution slowly decreased. This release of clindamycin can provide a quick prevention of bacterial growth. It can help to reduce the risk of infection. In addition, the use of antimicrobial coatings presupposes to the immediate release of antimicrobial agents by targeted delivery and maintenance of high concentrations for a long time.

\section{Conclusions}

PVP-based coatings show greater mechanical resistance than PVA coatings. Therefore, coatings made of PVP containing an antimicrobial agent, clindamycin, were used for microbiological tests. In addition, the release rate of clindamycin from the coatings was checked. The conducted study proved that the PVP can be used as a drug-eluting coating. Coatings made based on 3\% content of PVP containing an antimicrobial drug can be used in medical applications. The use of PVP in polymer coatings allows the rapid release of an antimicrobial agent (clindamycin), which is beneficial in the use of these coatings in short-term catheterization, for example, during surgical procedures. PVP-clindamycin-based coatings prepared in this studies show growth inhibition for three different bacterial strains which are involved in catheter-related infections. The most common pathogens isolated in catheter-related infections are staphylococci, particularly coagulase-negative staphylococci and enterococci, mainly 

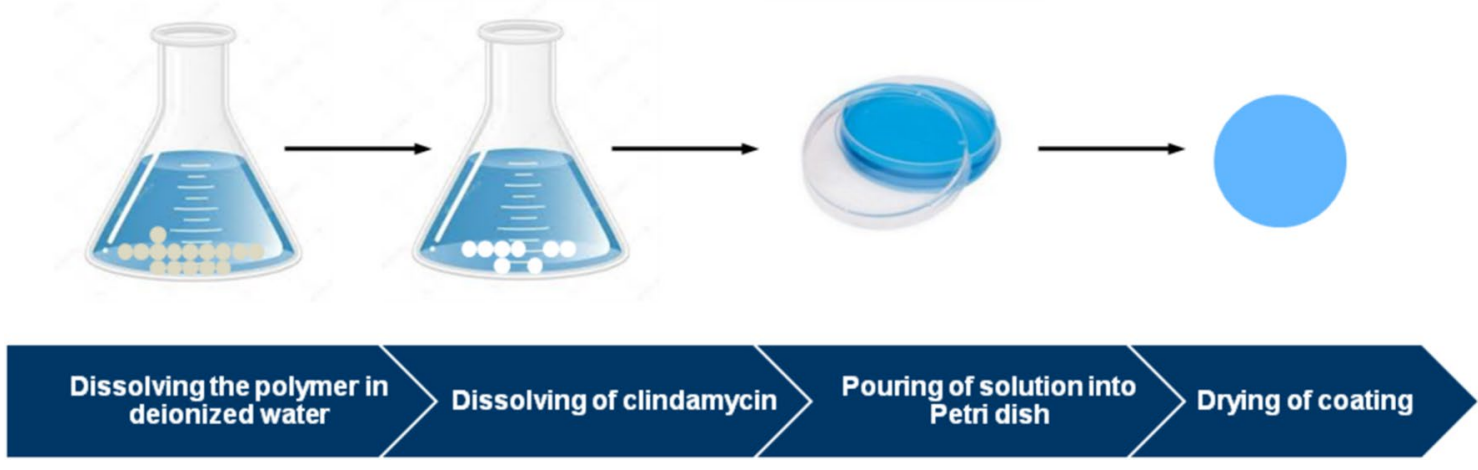

Fig. 3 The stages of polymer coatings preparation

S. aureus and Candida species. Before 1986, S. aureus was the most frequently reported pathogen [8].

Other studies on the release of antibiotic (ciprofloxacin) in the polymer coating (based on PVA) have been found in the literature. These coatings were prepared and applied to the surface of the biopsy needles [9].

\section{Experimental}

Polyvinyl alcohol and polyvinylpyrrolidone were purchased from Sigma-Aldrich (USA). Clindamycin was purchased from Pfizer (USA) in the form of tablets labeled to contain $300 \mathrm{mg}$ clindamycin per tablet. Saline solution $(0.9 \%)$ was purchased from Polpharma (Poland). Acetonitrile (HPLC grade) and formic acid (FA; $>98 \%)$ were purchased from Merck (Germany). Acetonitrile (LC-MS grade) was purchased from VWR Chemicals (USA). Ultrapure water was prepared using HPL5 system from Hydrolab (Poland).

\section{Sample preparation}

PVA and PVP coatings were prepared by dissolving the appropriate amount of polymer in deionized water. These solutions consisted of $1,3,5$, and $7 \%$ of polymer, respectively. After the dissolution of the entire polymer (using mixing and heating), the solutions were poured into $9 \mathrm{~cm}$ Petri dishes for drying. The coating with the best properties was then selected and shells were prepared with the addition of clindamycin, respectively, of $1,3,5 \%$ concentrations for the selected content of polymer. The stages of polymer coating preparation are shown in Fig. 3.

\section{Characterization of PVP coatings}

Coatings with different PVP concentrations were observed using optical microscopy from Bresser to assess their homogeneity. The degradation of coatings after the impact of $0.9 \% \mathrm{NaCl}$ was also tested. Mechanical properties of coatings were also examined. Tensile strength was studied using the universal testing machine Zwick and Roell Z020 according to PN-EN ISO 527-2:2012 with a crosshead speed of $100 \mathrm{~mm} / \mathrm{min}$ and measuring path of 60.35 .

\section{HPLC-MS}

An Agilent G1379B LC system that consisted of binary pump, an online degasser, an autosampler, and a thermostated column compartment coupled with 1100 Series LC/ MSD. Purospher® STAR RP-C18e $(125 \times 3 \mathrm{~mm}, 5 \mu \mathrm{m}$; Merck, Germany) column was used during analysis. The flow rate was $1 \mathrm{~cm}^{3} / \mathrm{min}$, injection volume was $5 \mathrm{~mm}^{3}$, and column temperature was $30^{\circ} \mathrm{C}$. As a mobile phase, water (component A) and acetonitrile (component B) both with $0.1 \%$ FA addition were used. The mobile phase was used in the following gradient elution: $0 \mathrm{~min}-15 \% \mathrm{~B}, 2 \mathrm{~min}-$ $15 \% \mathrm{~B}, 4 \mathrm{~min}-30 \% \mathrm{~B}, 6.5 \mathrm{~min}-30 \% \mathrm{~B}, 6.6 \mathrm{~min}-15 \%$ B. The ESI source was operated with positive ion mode. Nebulizer gas was set at 35 psi and drying gas temperature was set at $300^{\circ} \mathrm{C}$.

\section{Clindamycin release studies}

Drug release studies were conducted for clindamycin-modified coatings ( $5 \%$ addition of clindamycin in coatings). The prepared coatings were cut into squares $(5 \times 5 \mathrm{~mm})$ and were weighed. In the next stage, the prepared samples were placed in $0.9 \% \mathrm{NaCl}$ solution for 15,30 , and $60 \mathrm{~min}$, respectively. After a predetermined time, a sample solution was taken and tested by HPLC-MS (procedure 4.4). Each sample was analyzed by three replications. 


\section{Microbiology}

Antibacterial activities of clindamycin-PVP-based coatings (3\% PVP coatings with 1,3 , and 5\% addition of clindamycin) were evaluated against $E$. coli, $P$. aeruginosa, and $S$. aureus, using the disk agar diffusion method. Bacterial strains was obtained from collection of the Department of Molecular Biotechnology and Microbiology, Gdańsk University of Technology. Stock cultures were maintained by periodic subculture on nutrient agar slants which were stored at $4{ }^{\circ} \mathrm{C}$. Before each experiment, bacterial strains were refreshed by growing in LB broth medium and incubated for $24 \mathrm{~h}$ at $37^{\circ} \mathrm{C}$. LB broth medium was prepared by dissolving $10 \mathrm{~g} \mathrm{NaCl}, 10 \mathrm{~g}$ peptone, and $5 \mathrm{~g}$ yeast extract in a liter of distilled water and then autoclaved $\left(121^{\circ} \mathrm{C}, 1.5 \mathrm{~atm}\right.$, $20 \mathrm{~min}$ ) and cooled to room temperature. All reagents were supplied by BTL Sp. z o.o., Lodz, Poland [10]. Then, the bacterial cultures were diluted tenfold using LB medium, and $0.1 \mathrm{~cm}^{3}$ of the bacterial suspensions were spread over the LB agar plates and incubated at $37{ }^{\circ} \mathrm{C}$ for $24 \mathrm{~h}$. The polymeric coatings were cut, sterilized with $70 \%$ ethanol and followed by drying under UV lamp (30 min). The coatings were gently placed on the agar plates using forceps, and the plates were incubated at $37^{\circ} \mathrm{C}$ for $24 \mathrm{~h}$. After the incubation, the presence or absence of zones of bacterial growth inhibition around samples of polymeric coatings was checked. Antibacterial activities of the polymer coatings were tested by three replications repeatedly. During the microbiological test, three pieces of polymer coatings were placed on the surface of each agar plate.

Acknowledgements The authors are very grateful to the Professor $\mathrm{H}$. Cieśliński for his careful and helpful comments.
Open Access This article is distributed under the terms of the Creative Commons Attribution 4.0 International License (http://creativeco mmons.org/licenses/by/4.0/), which permits unrestricted use, distribution, and reproduction in any medium, provided you give appropriate credit to the original author(s) and the source, provide a link to the Creative Commons license, and indicate if changes were made.

\section{References}

1. Warren JW (2001) Int J Antimicrob Agents 17:299

2. Dohnt K, Sauer M, Müller M, Atallah K, Weidemann M, Gronemeyer P, Rasch D, Tielen P, Krull R (2011) J Microbiol Methods $87: 302$

3. Kowalczuk D, Ginalska G, Golus J (2010) Int J Pharm 402:175

4. Jamal M, Ahmad W, Andleeb S, Jalil F, Imran M, Nawaz MA, Hussain T, Ali M, Rafiq M, Kamil MA (2018) J Chin Med Assoc 81:7

5. Dayyoub E, Frant M, Pinnapireddy SR, Liefeith K, Bakowsky U (2017) Int J Pharm 531:205

6. Singha P, Locklin J, Handa H (2017) Acta Biomater 50:20

7. Bauer A, Perry DM, Kirby WMM (1959) AMA Arch Intern Med 104:208

8. Bouza E, Burillo A, Muñoz P (2002) Clin Microbiol Infect 8:265

9. Sieczkowski M, Gibas A, Wasik A, Kot-Wasik A, Piechowicz L, Namieśnik J, Matuszewski M (2017) Technol Cancer Res Treat 16:1038

10. Kucińska-Lipka J, Gubańska I, Lewandowska A, Terebieniec A, Przybytek A, Cieśliński H (2019) Polym Bull 76:2725

11. Gilmore BF (2011) Antimicrobial ionic liquids. In: Kokorin PA (ed) Ionic liquids: applications and perspectives. InTech, UK

Publisher's Note Springer Nature remains neutral with regard to jurisdictional claims in published maps and institutional affiliations. 